Article

\title{
Smart City Projects Boost Urban Energy Efficiency in China
}

\author{
Zhengge Tu ${ }^{1,2}$, Jiayang Kong ${ }^{1,2}$ and Renjun Shen ${ }^{1,2, * \mathbb{D}}$ \\ 1 School of Economics and Business Administration, Central China Normal University, Wuhan 430079, China; \\ zhenggetu@ccnu.edu.cn (Z.T.); jiayangkong@ccnu.edu.cn (J.K.) \\ 2 Research Center of Low-carbon Economy and Environmental Policies, Central China Norma University, \\ Wuhan 430079, China \\ * Correspondence: renjunshen@ccnu.edu.cn
}

\section{check for}

updates

Citation: Tu, Z.; Kong, J.; Shen, R. Smart City Projects Boost Urban

Energy Efficiency in China.

Sustainability 2022, 14, 1814. https://

doi.org/10.3390/su14031814

Received: 8 January 2022

Accepted: 3 February 2022

Published: 5 February 2022

Publisher's Note: MDPI stays neutral with regard to jurisdictional claims in published maps and institutional affiliations.

Copyright: () 2022 by the authors Licensee MDPI, Basel, Switzerland. This article is an open access article distributed under the terms and conditions of the Creative Commons Attribution (CC BY) license (https:// creativecommons.org/licenses/by/ $4.0 /)$.

\begin{abstract}
Policy makers around the world are turning to smart city projects in an effort to address the challenges of population growth, energy efficiency, and environmental sustainability. Previous studies have evaluated the effect of smart city projects on air quality. However, evidence on the impact of the projects on energy efficiency remains unclear. This study gathered prefecture-level city panel data in China, and used three strategies, namely a difference-in-differences estimator, a matching difference-in-differences estimator, and a counterfactual model using a machine learning algorithm, to assess the impact of smart city projects on energy efficiency. This study reported similar results across these strategies above. That is, after the introduction of a smart city project, energy efficiency had a remarkable and sizeable increase, ranging from 4 to 7 per cent. Moreover, this study shows that the effects of smart city projects increased over time. In addition, this study found that the effects varied according to the characteristics of the cities.
\end{abstract}

Keywords: smart city project; energy efficiency; difference-in-differences estimator; matching difference-in-differences estimator; counterfactual model

\section{Introduction}

According to some predictions issued by the World Bank, by the year of 2050 approximately 70 per cent of population across the globe will be living in urban areas [1] Urbanization brings with it increased human, business, and industrial activities, which contribute to economic growth, but also result in a rising demand for energy, which places particularly large pressure on local energy supply [2-6]. In particular, this pressure is expected to occur in developing countries, such as China, where people are progressively migrating from rural to urban areas [7-11].

Policy makers across the world are searching for solutions to improve energy efficiency in an effort to address the energy crises induced by urbanization. Smart city projects are a possibility for meeting their needs [12]. The exact format could be distinguished across countries and cities. Most smart city projects, however, integrate digital technologies into sustainable development goals $[13,14]$. Although academic attention on the project is growing rapidly, there is quite surprisingly very little work that assesses the impact of smart city projects on energy efficiency [15-17]. This paper plans to fill this gap in the academic market. For this purpose, this study used prefecture-level city data from China to investigate the impact of smart city projects on energy efficiency.

There are two reasons why this paper focused on China. First, it is the most populated country in the world (1.4 billion people in 2019), with a fast-growing economy that has led it to be the largest energy consumer in the world [18]. Based on data from 2019, China consumed about 1.4 thousand joules, accounting for around 20 per cent of world energy consumption [19]. China is by far the global biggest coal consumer, the second largest oil guzzler, and one of the top five natural gas consumers in the world [20]. Thus, the efforts of China to improve energy efficiency are crucial to global energy and climate landscapes. 
Second, China is one of the first countries in the world to launch a smart city project, and the Chinese government is running the largest smart city project around the world [21,22]. By 2017, 99 cities (nearly one-third of Chinese cities) had participated in building a smart city. If smart city projects indeed work in China, this study is expected to show a substantial boost in energy efficiency.

To assess the impact of smart city projects on energy efficiency, this study acquired prefecture-level city panel data in China. This study used three strategies, namely a difference-in-differences estimator, a matching difference-in-differences estimator, and a model of the counterfactual using a machine learning algorithm, to explore the variation in energy efficiency in cities participating in smart city projects relative to cities not participating. The estimated results are consistent with our expectation that smart city projects would improve energy efficiency. Moreover, the estimated results were analogous to each other across the three strategies. The estimates show that a city that participated in a smart city project achieved about 5 percentage points lower energy consumption per unit of GDP after the implementation of the project than a city that did not participate. In addition, the effect of smart city projects depends on the characteristics of the cities. This study shows that smart city projects are more conductive to energy efficiency improvement in cities with higher GDP per capita, more secondary industrial output, and lower population levels.

This study is distinguished from the small existing literature on smart city projects. Previous studies focused on how to design and build a smart city, whereas this study pays close attention to the impact of smart city projects on energy consumption $[23,24]$. Additionally, this study is different from that of Yu and Zhang [25]. They assessed the effectiveness of smart city projects on energy consumption based on data envelopment analysis. However, the selection of the input indices for data envelopment analysis depends on the researchers, which makes their measure of energy efficiency not objective. In comparison, the indicator of energy efficiency in this study combines information from various forms of data, including satellite imaginary and energy consumption data at a provincial level, and it is thus more objective.

Finally, the findings in this paper provide insights for policy makers on how smart city projects affect energy consumption. This will help them design better energy policies, which are substantially important for building a better future.

\section{Methods}

Energy consumption per unit of Gross Domestic Product. The main indicator used in this study was energy consumption per unit of Gross Domestic Product (GDP) as a measure of energy efficiency. Following Zhao et al., the index combines information from various forms of data, including the Defense Meteorological Satellite Program's Operational Linescan System (DMSP-OLS) nighttime light imagery of the earth, the Suomi National Polar-orbiting Partnership (NPP) Visible Infrared Imaging Radiometer Suite (VIIRS) composite data from the National Oceanic and Atmospheric Administration, energy consumption data at the provincial level from the China Energy Statistical Yearbook, and GDP data at the city level from the China City Statistical Yearbook.

To evaluate city-level energy consumption per unit of GDP data, this study first integrated the DMSP-OLS nighttime stable light data and the NPP-VIIRS composite data [26]. Next, this study calculated the number of city night lights. This study then divided provincial-level energy consumption data into city-level data using city night lights as a share of the province's night lights. Finally, this study divided city energy consumption by its GDP to obtain the energy consumption per unit of GDP at the city level. During this process, fluctuations in price were removed, and the base year in calculating real GDP was 2003. A lower energy consumption per unit of GDP represents better energy efficiency. Here, one unit represents 10,000 yuan in 2003 prices.

Smart city projects. All of the cities' smart city plans were directly issued by the central government. This study obtained the list of participating cities from the Ministry of Housing and Urban-Rural Development. Although most of the cities participating in 
smart city projects are prefecture-level cities, some are county-level cities or urban districts. In this study, cities would be designated as participants when the whole prefecture-level city adopted a smart city project. Their geographical distribution and policy timing are shown in Panels A and B of Figure 1, respectively.

\section{A. Treatment status}

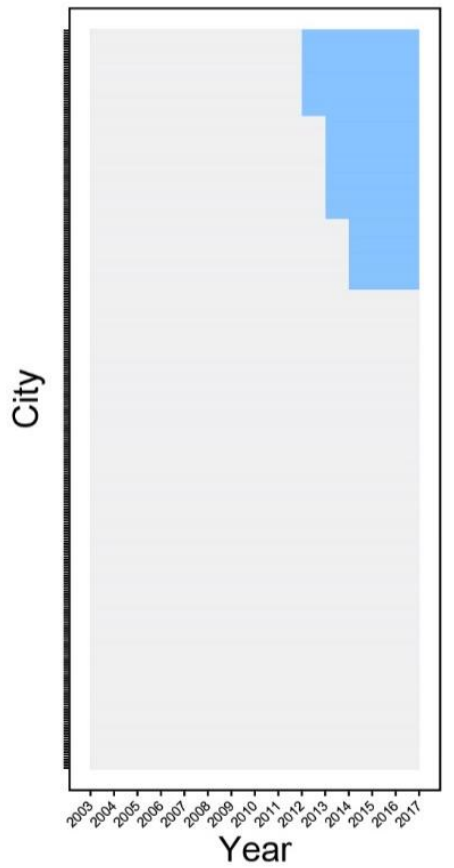

\section{B. Map of energy consumption in China between 2003 and 2017}

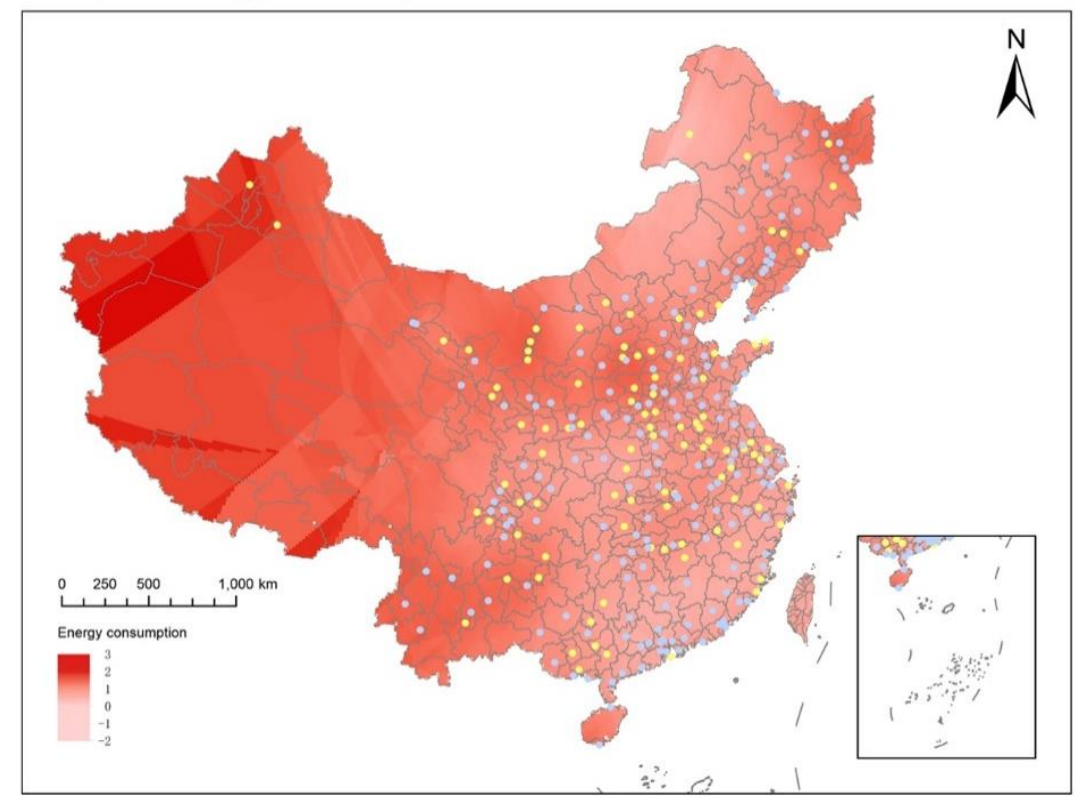

Figure 1. Timing of launching a smart city project and energy consumption per yuan portrayed on a map of China. The left panel: The treatment status of cities through our study period (2003-2017) are shown, with the blue shadow representing treated status and the gray shadow representing control status. The right panel: Energy consumption per yuan of GDP on average during the study period (2003-2017), with the yellow points representing treated cities and the blue points control cities. (A) Treatment status. (B) Map of energy consumption in China between 2003 and 2017.

Control variables. The control variables included population density, the share of industrial production in GDP, and the share of the industrial sector in GDP. This study acquired these data from the China City Statistical Yearbook. The population density represents human and business activity. The share of industrial production in GDP represents a scale of industry. The share of the industrial sector in GDP represents industrial structure.

Classification. On the basis of the Sustainable Development Plan for Resource-Based Cities, this study divided cities into two groups, one labeled "resource-based city" and the other labeled "not resource-based city". This study also classified cities into different subgroups according to the National Old Industrial Base Adjustment and Renovation Plan. For example, in our sample, some cities were considered as old industrial base while others were not. In addition, in some exercises, this study grouped cities in three geographical regions following the National Bureau of Statistics classification. These regions are Eastern China, Central China, and Western China. Finally, based on the Huai River rule, this study constructed a dichotomous measure which classifies cities as in "the North in China" or "the South in China".

Summary statistics. Descriptive statistics for the variables used in this analysis for all the cities, namely those cities that participated in smart city projects and those that did not, are reported in Table A1.

Models. This study employed three strategies to identify the causal effect of smart city projects on energy efficiency. 
Baseline model, that is, the difference-in-differences strategy. This study first used a standard difference-in-differences estimator to calculate the relative change in energy efficiency between cities that adopted a smart city project and cities that did not. The fitted model is as follows:

$$
E_{c t}=S_{c t} \times \beta+X_{c t} \times \gamma+\alpha_{c}+\delta_{t}+\varepsilon_{c t}
$$

where $E_{c t}$ is energy consumption per unit of GDP, which is our indicator of energy efficiency in city $c$ at time $t$, and $S_{c t}$ is our dichotomous measure of whether city $c$ at time $t$ participated in a smart city project. The specification includes a series of control variables $\boldsymbol{X}_{c t}$ such as population density, the share of industrial production in GDP, and secondary industry as percentage of GDP. $\alpha_{c}$ is city-fixed effects and $\delta_{t}$ is year-fixed effects.

The city-fixed effects, $\alpha_{c}$, would include the effect of any time-invariant characteristics of cities, such as geographical location and climate condition, whereas the year-fixed effects, $\delta_{t}$, could be used to capture a common shock to all cities in that year, such as the 2008 Financial Crisis and the trend in energy consumption per unit of GDP. The parameter measures the difference in energy consumption between treated cities (those that participated in the project) and control cities (those that did not participate) before and after the implementation of the smart city project.

Under the assumption that, in the absence of a smart city project, the treated and the control cities should share a common trend in energy consumption, this study could investigate whether smart city projects influenced energy consumption or not. This study expected $\beta$ to be negative, as smart city projects would simulate "green" technological innovation, consequently resulting in remarkable decreases in energy consumption.

Matching difference-in-differences strategy. Although the first strategy adjusts for the time-unvarying characteristics of cities and partly accounts for the declining trend in energy consumption preceding the implementation of a smart city project, it does not address selection bias, that is, the propensity to participate in a smart city project, which might confound these estimates of the impact of smart city projects on energy consumption. In addition, the standard difference-in-differences estimator relies greatly on the linear assumption. Linearity implies that the effectiveness of smart city projects is the same no matter when cities participate, which restricts the evolution of energy consumption after the project's implementation. To address these challenges, this study adopted an alternative strategy to estimate the impact of smart city projects. Next, this study outlines two alternative approaches for measuring the causal effect of smart city projects on energy efficiency.

For the first approach, this study first modeled and estimated the propensity score through a logistic regression of the probability of participation in a smart city project on the aforementioned observed characteristics of the cities. This study then matched treated cities with control cities based on the propensity scores, and calculated the causal effect based on the matched sample while adjusting for city- and year-fixed effects.

For the second approach, this study first modeled and estimated the propensity score through a logistic regression of the probability of participation in a smart city project on the aforementioned observed characteristics of cities. Next, this study considered the propensity scores as the weights given to different observations to recover two imaginary populations, one for treated cities and another for control cities. Finally, this study calculated the causal effect on the basis of the two imaginary populations while controlling for city- and year-fixed effects.

The first approach is called a propensity score matching difference-in-differences estimator, and the second approach is called an inverse probability weighting difference-indifferences estimator, in the literature on potential outcomes.

Modelling the counterfactual. The previous two strategies remove confounding effects for the estimated results and explain the trend in energy efficiency before the introduction of a smart city project, but they still suffer from omitted variable bias caused by unobserved time-varying variables. Here, this study introduced three machine learning algorithms to tackle this problem. The first approach used a least square regression of energy efficiency on 
the aforementioned three observable characteristics of cities (population density, the share of industrial production in GDP and secondary industry as percentage of GDP) for cities not participating in a smart city project to construct a counterfactual for cities participating in the project.

The second approach followed Gobillon and Magnac [27], and $\mathrm{Xu}$ [28], in estimating the effect of smart city projects on energy efficiency adjusted for underlying time change factors. This study implemented a factor argument model to account for these potential time-varying variables using observations under the control condition, which is an extension of the synthetic control method. This study then predicted the treated counterfactual using coefficients obtained from the above model. This generated control cities comparable to treated cities.

The third approach built on work by Athey et al. [29] and treated the unobserved control condition for the treated cities as missing values that could be inferred from a latent factor structure. Intuitively, this approach removes the confounding effects of any time-varying variables and re-weighs our data to produce control cities comparable to cities that participated in a smart city project. The estimator is also not dependent on the linear assumption; this gives this study more flexibility to explore the time pattern of the impacts of smart city projects on energy efficiency.

\section{Results}

Impact of smart city projects on energy efficiency. In order to quantify the impacts of smart city projects on energy efficiency, this study estimated the relative change in energy consumption per unit of GDP in cities participating in the project and relative to cities not participating.

Baseline results. Columns (1) to (4) of Table 1 present these estimates for the basic specifications using a difference-in-differences estimator. Column (1) shows that around the introduction of a smart city project, energy consumption per unit of GDP decreased for participating cities by about 5 percentage points more than for cities not participating. The coefficient of smart city projects indicates that after project implementation the improvement of energy efficiency was better for participating cities, suggesting that smart city projects had a positive effect on energy efficiency.

In the second column of Table 1, this study controlled for population density, the share of industrial production in GDP, and the share of the industrial sector in GDP. Although the confidence in the causal effect of smart city projects on energy efficiency was improved by reducing the potential omitted variable bias, the overall amount of reduction in percentage of energy consumption per unit of GDP was close to that found in Column (1). The standard error of the coefficient of smart city projects was smaller.

In Columns (3) and (4), this study estimated the impact of smart city projects on energy efficiency adjusted for province-specific year shocks, with robust standard errors at the alternative cluster level. In Column (3), which is the preferred specification, this study used robust standard errors clustered at the city level. The coefficient on smart city projects indicates that, after controlling for province-specific year shocks and clustering standard errors at the city level, the project improved energy efficiency by about 4.5 percentage points. In Column (4), this study clustered standard errors at the provincial level. The result was the same as that found in Column (3), while the standard error was now larger, indicating that the estimates are remarkably robust whether standard errors are clustered at the city or the provincial level. 
Table 1. The effects of smart city projects on energy consumption per yuan of GDP in logs.

\begin{tabular}{|c|c|c|c|c|c|c|c|c|c|c|c|c|}
\hline & \multicolumn{4}{|c|}{ DID Estimates } & \multicolumn{4}{|c|}{ PSM-DID Estimates } & \multicolumn{4}{|c|}{ IPW-DID Estimates } \\
\hline & (1) & (2) & (3) & (4) & (5) & (6) & (7) & (8) & (9) & (10) & (11) & (12) \\
\hline Smart city projects & $\begin{array}{l}-0.050 * * \\
(0.0212)\end{array}$ & $\begin{array}{l}-0.049 * * \\
(0.0197)\end{array}$ & $\begin{array}{c}-0.045^{* * *} \\
(0.0156)\end{array}$ & $\begin{array}{l}-0.045^{* *} \\
(0.0177)\end{array}$ & $\begin{array}{l}-0.068^{* * *} \\
(0.0198)\end{array}$ & $\begin{array}{l}-0.066^{* * *} \\
(0.0188)\end{array}$ & $\begin{array}{l}-0.050 * * * \\
(0.0156)\end{array}$ & $\begin{array}{l}-0.050 * * \\
(0.0184)\end{array}$ & $\begin{array}{l}-0.048^{* *} \\
(0.0194)\end{array}$ & $\begin{array}{l}-0.047^{* *} \\
(0.0183)\end{array}$ & $\begin{array}{l}-0.043^{* * *} \\
(0.0147)\end{array}$ & $\begin{array}{l}-0.043^{* *} \\
(0.0166)\end{array}$ \\
\hline R-squared & 0.975 & 0.977 & 0.986 & 0.986 & 0.976 & 0.977 & 0.985 & 0.985 & 0.976 & 0.978 & 0.986 & 0.986 \\
\hline Control variables & & Yes & Yes & Yes & & Yes & Yes & Yes & & Yes & Yes & Yes \\
\hline City-fixed effects & Yes & Yes & Yes & Yes & Yes & Yes & Yes & Yes & Yes & Yes & Yes & Yes \\
\hline Year-fixed effects & Yes & Yes & Yes & Yes & Yes & Yes & Yes & Yes & Yes & Yes & Yes & Yes \\
\hline $\begin{array}{c}\text { Province } \times \text { Year-fixed } \\
\text { effects }\end{array}$ & & & Yes & Yes & & & Yes & Yes & & & Yes & Yes \\
\hline $\begin{array}{l}\text { Standard errors are } \\
\text { clustered at city level } \\
\text { Standard errors are }\end{array}$ & Yes & Yes & Yes & & Yes & Yes & Yes & & Yes & Yes & Yes & \\
\hline $\begin{array}{c}\text { clustered at province } \\
\text { level }\end{array}$ & & & & Yes & & & & Yes & & & & Yes \\
\hline Observations & 4215 & 4215 & 4140 & 4140 & 3980 & 3980 & 3892 & 3892 & 4215 & 4215 & 4140 & 4140 \\
\hline Cities in sample & 281 & 281 & 281 & 281 & 280 & 280 & 280 & 280 & 281 & 281 & 281 & 281 \\
\hline
\end{tabular}


Panel A of Figure 2 depicts the evolution of the effects on energy consumption per unit of GDP in cities participating in a smart city project at time 0 relative to other cities not participating in the project at the time, together with $95 \%$ confidence intervals for these estimates. The plot of time path reveals that the gap in energy efficiency between cities participating and cities not participating in smart city projects increased monotonically after project implementation.

A. DID estimator

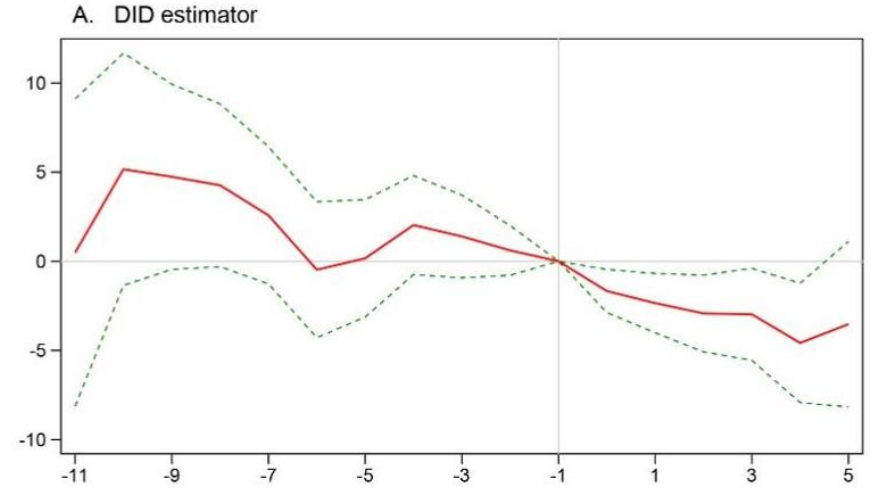

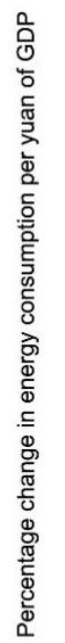

B. PSM-DID estimator

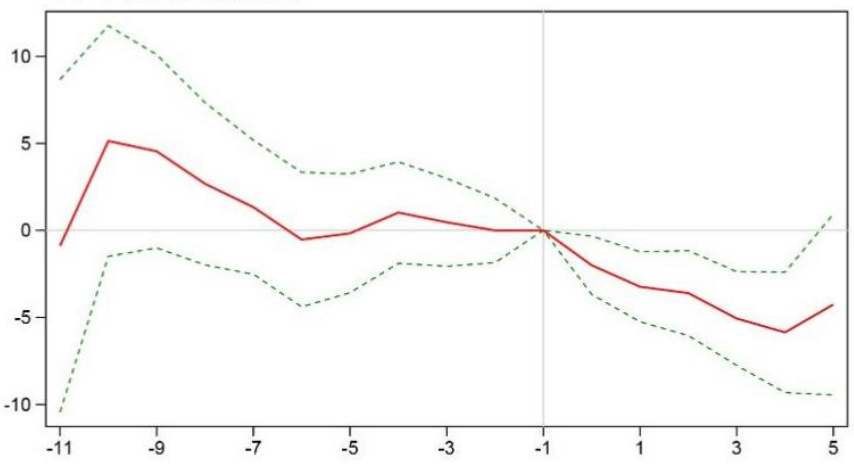

C. IPW-DID estimator

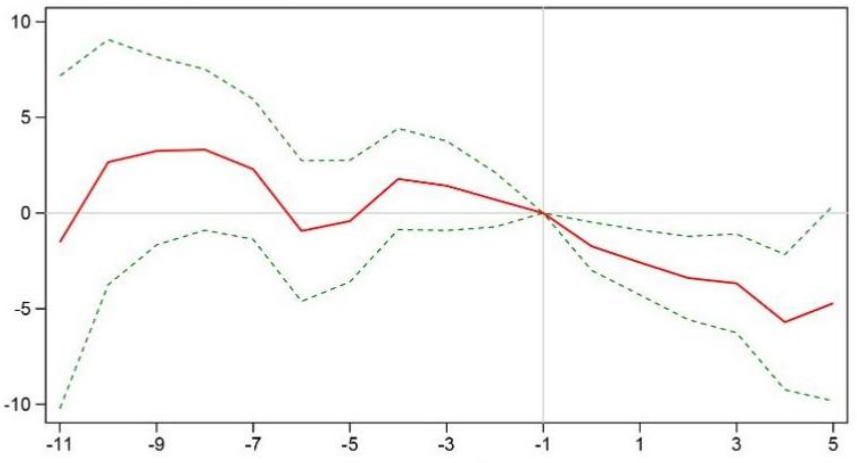

Years around smart city building

Figure 2. The effect of smart city projects. (A) The results are from the difference-in-differences estimator. (B) The results are from the propensity score matching difference-in-differences estimator. (C) The results are from the inverse probability weighting difference-in-differences estimator. The red solid line plots the estimated average effect of smart city project on energy consumption, along with a $95 \%$ confidence interval in the green dash line. Time (in years) relative to the introduction of a smart city project runs on the horizontal axis. 
Overall, these results show that, around the introduction of smart city projects, these participating cities experienced a gradual decline in energy consumption per unit of GDP. That is, the smart city project had a significant and robust positive effect on energy efficiency. Motivated by the above analyses, this study refers to Column (3) in Table 1 as our basic specification, and pays close attention to the specification in the rest of this study for robustness and heterogeneity.

Treatment effects and semi-parametric estimates. The rest of Table 1 presents various treatment effect estimates from semi-parametric estimators. These results are very analogous to the preferred specification in Column (3).

Panel B of Figure 2 plots the estimates obtained from the propensity score matching difference-in-differences estimator. The red solid line represents the estimated impacts of smart city projects on energy consumption per unit of GDP over time. The green dash line represents $95 \%$ confidence intervals. This study shows a gradual decrease in energy consumption, plateauing between 3 and 5 years at about 5 percentage points.

Columns (5) to (8) in Table 1 also summarize the estimates by presenting the average treatment effect of smart city projects on energy consumption. The settings in these columns are the same as those in Columns (1) to (4). The estimated results in these columns show that after the project's introduction, energy consumption per unit of GDP was reduced from 4.3 per cent to 6.8 per cent. This confirms that smart city projects improved energy efficiency.

Panel C of Figure 2 plots the estimates from the inverse probability weighting differencein-differences estimator. The time path of the effects is similar to that in Panel B of Figure 2, with a peak effect at about 6 percentage points between 3 and 5 years later. This study also summarized these estimates in Columns (9) to (12) of Table 1, whose settings are the same as those in Columns (1) to (4), and they were close to these estimated results in Column (5) to (8).

On the whole, the results give this study confidence. That is, these results are robust and do not rely on the linearity assumption.

Counterfactual scenarios and non-parametric estimates. Figure 3 provides graphical evidence of the effect of smart city projects based on machine learning algorithms that produce counterfactuals for cities participating in the project.

Panels A through C of Figure 3 separately plot the estimates from the fixed-effects, interactive fixed-effects and matrix-completion algorithms combined with the difference-indifferences estimator. The red solid line represents the differences in energy consumption per unit of GDP between participating cities and the counterfactual over time. The green dash line represents 95\% confidence intervals calculated from bootstrapped standard errors. The trends in energy consumption in Panels A though $C$ were similar. That is, the energy consumption per unit of GDP decreased dramatically around the introduction of a smart city project. The effects of the project peaked at about 10 percentage points in the fifth year after the introduction in Panels A and C, while the effect reached the highest point at about 5 per cent in the second year after the introduction in Panel B.

Panels D through F of Figure 3 depict the estimates, obtained from the aforementioned three algorithms combined with the propensity score matching difference-in-differences estimator, respectively. The patterns in Panels D though F were very close to each other, with downward trends in energy consumption and impacts of smart city projects on energy efficiency that plateaued at about 10 percentage points in the fifth years after the introduction. 

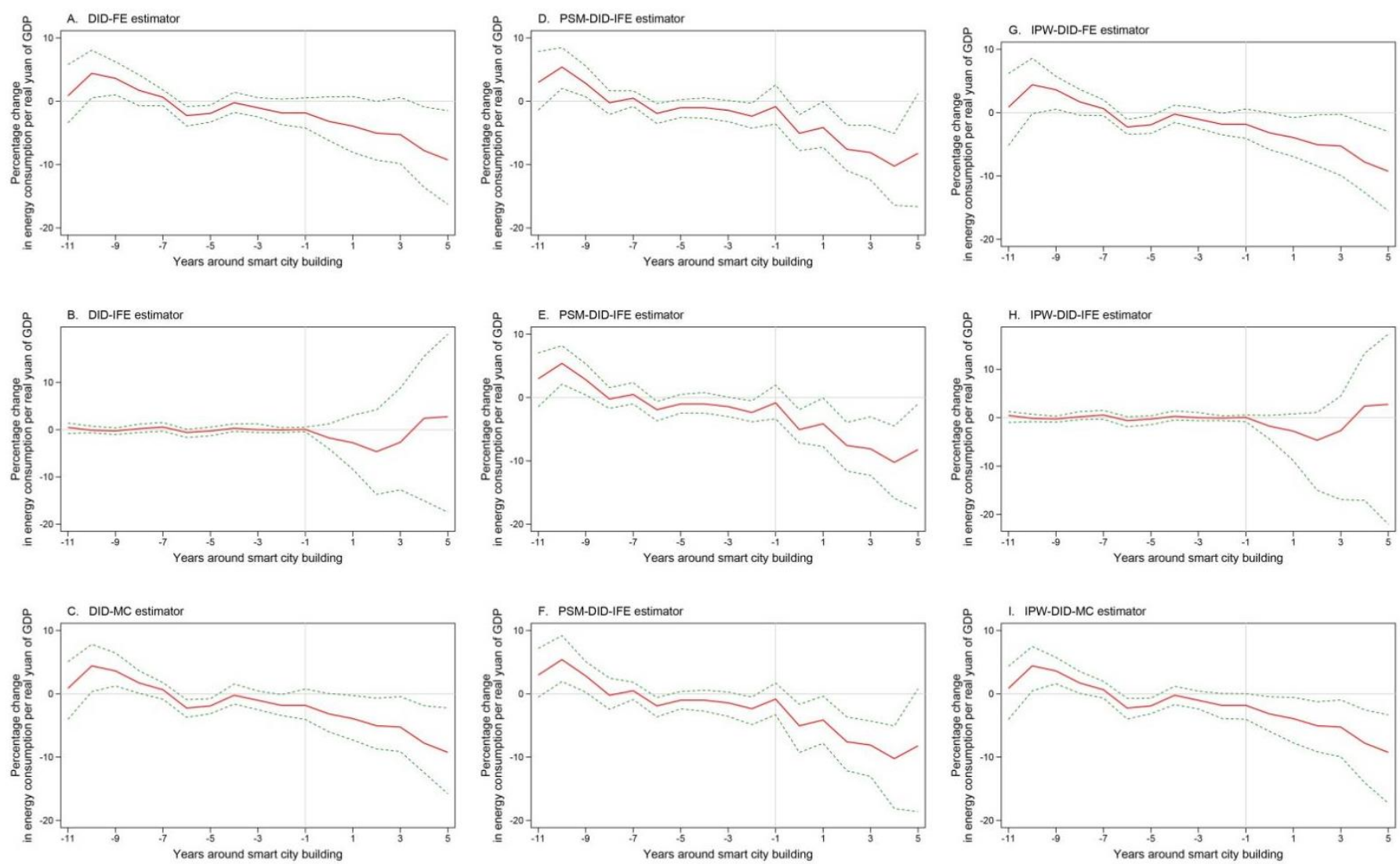

Figure 3. The effect of smart city projects on energy consumption. (A) The results are from the fixedeffects algorithm combined with the standard difference-in-differences estimator. (B) The results are from the interactive fixed-effects algorithm combined with the standard difference-in-differences estimator. (C) The results are from the matrix-completion algorithm combined with the standard difference-in-differences estimator. (D) The results are from the fixed-effects algorithm combined with the propensity score matching difference-in-differences estimator. (E) The results are from the interactive fixed-effects algorithm combined with the propensity score matching difference-in-differences estimator. (F) The results are from the matrix-completion algorithm combined with the propensity score matching difference-in-differences estimator. (G) The results are from the fixed-effects algorithm combined with the inverse probability weighting difference-in-differences estimator. $(\mathbf{H})$ The results are from the interactive fixed-effects algorithm combined with the inverse probability weighting difference-in-differences estimator. (I) The results are from the matrix-completion algorithm combined with the inverse probability weighting difference-in-differences estimator. The red solid line plots the estimated average effect of smart city projects on energy consumption, along with a 95\% confidence interval in the green dash line. Time (in years) relative to the introduction of a smart city project runs on the horizontal axis.

Panels G through I of Figure 3 present the inverse probability weighting differencein-differences estimates based on the counterfactual from machine learning algorithms. These results were similar to the previous results. Once again, there was evidence of a dip in energy consumption after the implementation of a smart city project. The effects of the project on energy efficiency peaked at about 10 percentage points in the fifth year in Panels $A$ and $C$, while the effect plateaued at about 5 percent in the second year after the project's implementation.

Not only were these estimates, which were obtained from non-parametric estimators, very analogous with each other, but they were also similar to the effect of smart city projects on energy consumption from baseline models and the semi-parametric estimator, whose results are presented in Table 1. The congruence between the estimates from the different approaches increases the credibility and reliability of the results that smart city projects were 
beneficial in reducing energy consumption. In the rest of this paper, this study focuses on the desired specification, which is Column (3) in Table 1, for robustness and heterogeneity.

Tests for parallel trends. The estimation of the effect of smart city projects on energy efficiency was based on the difference-in-differences study design, which requires that there be no differential trends in energy consumption between cities adopting a smart city project and cities not adopting the project before the project's implementation. This study performed an event study analysis to probe the trends in energy consumption for both groups preceding the project's introduction and to determine whether the differencein-differences study design is desirable. These findings are presented in Figures 2 and 3, and show that there were no statistically significant gaps in trends between treatment and control groups. This implies that the treatment and control groups are comparable, which increases this study's confidence that smart city projects did improve energy efficiency.

Robustness. Here, this study planned to investigate the robustness of these results. The results are presented in Figure 4: Panels A and D, that is, the left column, depict the results from the difference-in-differences estimator; Panels B and E, that is, the middle column, plot the results from the propensity score matching difference-in-differences estimator; Panel $\mathrm{C}$ and $\mathrm{F}$ provide the results from the inverse probability weighting difference-indifferences estimator. In all the panels, the red solid line represents the upper and lower bounds of $95 \%$ confidence intervals corresponding to the different estimators in our preferred specification.
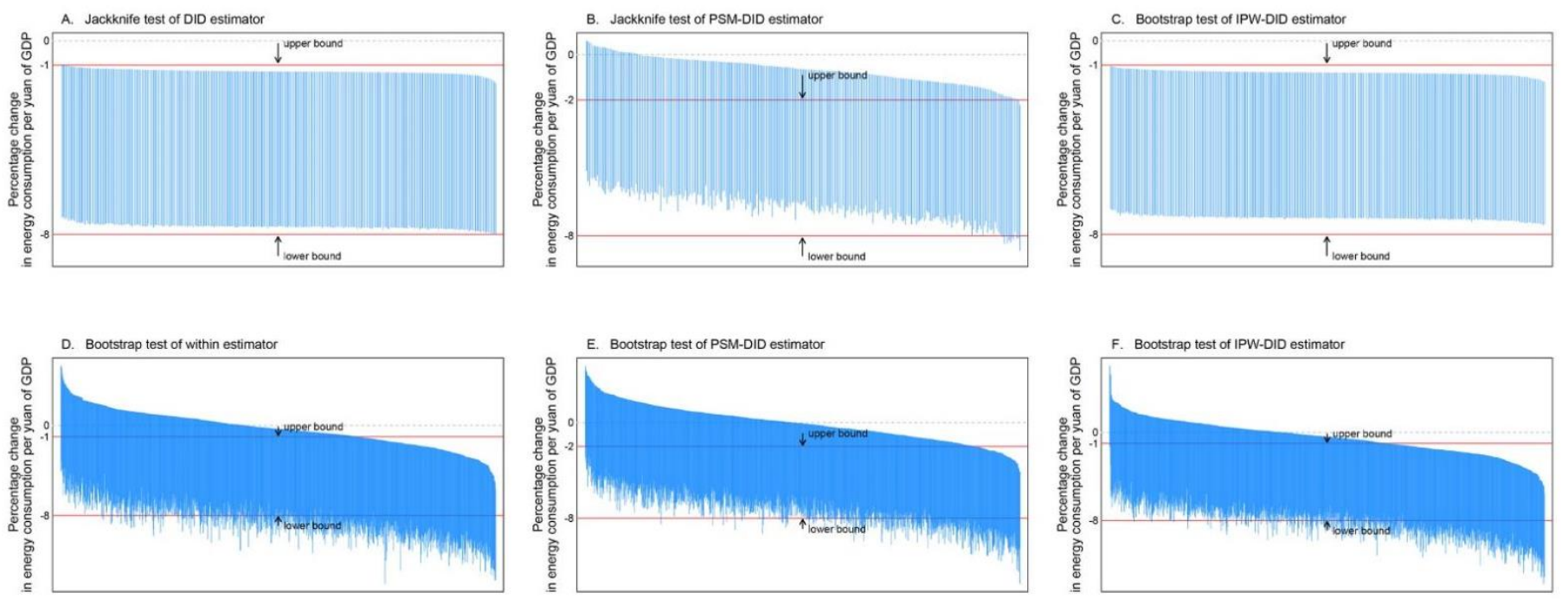

Figure 4. Robustness test for the effect of smart city projects on energy consumption. (A) Jackknife test for the standard difference-in-differences estimator. (B) Jackknife test for the propensity score matching difference-in-differences estimator. (C) Jackknife test for the inverse probability weighting difference-in-differences estimator. (D) Bootstrap test (1000 times) for the standard difference-indifferences estimator. (E) Bootstrap test (1000 times) for the propensity score matching difference-indifferences estimator. (F) Bootstrap test (1000 times) for the inverse probability weighting differencein-differences estimator. The blue shadow plots all 95\% confidence intervals for the effect of smart city projects across our tests, together with the $95 \%$ confidence interval of our preferred specification in red lines.

Jackknife test. The jackknife technique was used to investigate population uncertainty. These results are displayed in Panels A, B, and C, that is, the first row in Figure 4. These three effects from distinct estimators corresponding to the basic specification remained robust. All the $95 \%$ confidence intervals of the jackknife test were within the upper and lower bounds or contained them, while there were some fluctuations in the impact of smart city projects after excluding some cities. 
Bootstrap test. An alternative technique to explore population uncertainty is the bootstrap test. These results are provided in Panels D, E, and F. The patterns in these panels were similar to each other, and there was a systematic gap between the estimate from the bootstrap test and that from our preferred specification. Once again, the results illustrate that these estimates obtained from different estimators corresponding to our basic specification are robust.

Heterogeneity across cities. In Figure 5, this study explores whether characteristics of the cities would influence the effect of smart city projects on energy efficiency. The diamonds present the estimates from the distinct estimators based on our preferred specification, and the dash lines illustrate the uncertainty of the results: that is, Panel A reports the $90 \%$ confidence intervals, while Panel B presents the $95 \%$ confidence intervals. The congruence between the panels confirms that, excluding Eastern China and the old industrial bases, all the evidence points to a positive effect of smart city projects on energy efficiency.
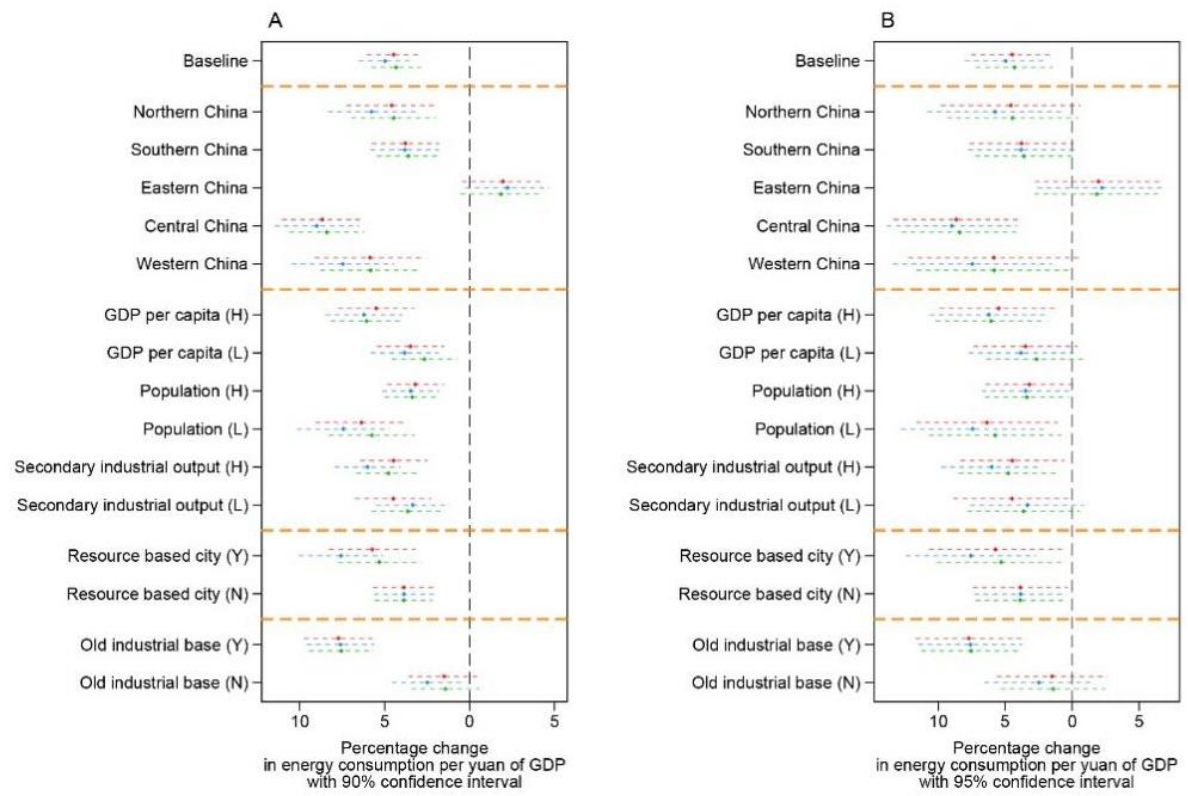

Figure 5. The heterogeneous effects of smart city projects on energy consumption. Red diamonds mark the estimated results from the standard difference-in-differences estimator, blue diamonds mark the estimated results from the propensity score matching difference-in-differences estimator, and green diamonds mark the estimated results from the inverse probability weighting difference-indifferences estimator. In Panel (A), the dash lines represent 90\% confidence intervals. In Panel (B), the dash lines represent $95 \%$ confidence intervals.

This study categorized cities into different geographical groups. First, this study compared north and south in China. Although there was no statistically significant difference between both groups, the effect of smart city projects was slightly better for cities in the north compared to cities in the south. This is consistent with our expectations because there are centralized heating infrastructures in the north in China that are usually considered energy-wasting systems. This study then investigated the effect of smart city projects in eastern cities, central cities, and western cities. The results show that the reduction in energy consumption for central cities was the greatest, followed by that for western cities, while there were no significant effects for eastern cities. This might be because energy efficiency in eastern cities was already good before the introduction of smart city projects, such that the project could not decrease energy consumption in these cities any further.

Moreover, economic development, population size, and industrial activity were expected to influence the effect of smart city projects. The results in the middle of Panels A and B show that the effect was larger in cities with higher GDP per capita, with the second largest effects in cities with high industrial outputs and the least significant effects in those 
with smaller populations. These findings imply that the effect of smart city projects could depend on economic development, while population size would negatively influence the project's effect. These specifications, however, need to be interpreted with caution because heterogeneity analyses do not provide a causal interpretation.

In addition, this study compared resource-based cities and non-resource-based cities. This study expected the impacts of smart city projects to be larger in resource-based cities because these cities could use the energy more inefficiently than other cities before the project's implementation, such that after the implementation of the project the decline in energy consumption per unit of GDP would be greater. The results shown in Panels A and B of Figure 4 confirm our conjecture, that is, that resource-based cities had a greater improvement in energy efficiency than non-resource-based cities.

Finally, as shown at the bottom of Panels A and B, this study examined the heterogeneous impacts according to whether one city was an old industrial base. This study shows that smart city project had a significant and positive impact on energy efficiency in old industrial bases, while there was no statistically significant impact in cities not belonging to the old industrial base. These findings are consistent with the fact that old industrial bases are usually referred to as energy-wasting cities that have worse energy efficiency than other cities. Consequently, after the project's implementation, old industrial bases experienced a more dramatic decrease in energy consumption than other cities.

The heterogeneity analysis results above imply that there exists variability in the effectiveness of smart city projects on energy efficiency resulting from certain characteristics of cities. Although the differences do not provide a causal explanation, they are beneficial for understanding the potential mechanisms through which smart city projects might affect energy consumption.

\section{Discussion}

Smart city projects have had a significant and robust positive impact on energy efficiency. This result is partly in line with that of Yu and Zhang, who reported on the boosting effects on energy efficiency ranging from 4.5 to 6.0 percentage points. The difference in the estimated results in this study and in their study might be due to the relatively more objective measurement of energy efficiency in this study compared with that in their study. If this is correct, future studies with objective energy efficiency could also demonstrate dramatic improvements that are analogous to the estimates of the impacts in this study.

The estimated results in this study also have important welfare implications. Previous studies have shown that improvements in energy efficiency are beneficial in reducing greenhouse gases and particulate matter, which are considered high-risk factors for various health outcomes, such as cognitive ability and life expectancy [30,31]. Thus, it is apparent that if smart cities do indeed improve energy efficiency, they would provide substantial social and health-related benefits.

In addition, the findings in this study are significant for policy-relevant issues. In the analysis of heterogeneity, this study noted that the effect of smart city projects was better in source-based cities or old industrial bases than in other cities. Not surprisingly, these results confirm that the utilization of energy is important for these cities, whose economic development deeply relies on traditional industry; the results also highlight that smart city projects help resource-based cities and old industrial bases to convert from energy-wasting cities to energy-efficient cities.

Finally, the analysis in this study shows that there was not significant effect of smart city projects in eastern cities. This could be explained by the initial high energy efficiency in Eastern China. An alternative explanation could be the greater willingness to admit the failure of a smart city project to improve energy efficiency in eastern cities. Additional studies on the effect of smart city projects on energy consumption in China should be conducted to understand this finding. 


\section{Conclusions}

In this study, the results show that once population size and industrial activity were controlled for in a fixed-effects difference-in-differences estimator, smart city projects had a significant and robust positive impact on energy efficiency. The result remains true with propensity score matching difference-in-differences estimators that model the propensity toward participating in smart city projects based on population size and industrial activity, as well as in inverse probability weighting difference-in-differences estimates that recover two target populations, one for the treatment group and another for the control group. The preferred specifications show that after the introduction of a smart city project energy consumption per unit of GDP decreased by about 5 percentage points.

Moreover, this study constructed a counterfactual for cities that participated in smart city projects using the information of cities not participating based on machine learning algorithms. By comparing the observed results and the counterfactual, this study corroborates our finding that smart city projects boosted energy efficiency.

The triangulation of evidence from parametric fixed-effects models, semi-parametric treatment effect estimators, and non-parametric counterfactual algorithms, all generating analogous estimates of the effectiveness of smart city projects on energy consumption per unit of GDP, gives much confidence that smart city projects had a significant and robust positive effect on energy efficiency.

Nevertheless, these results show that cities with higher GDP per capita, more secondary industrial output, and lower population levels experienced a greater reduction in energy consumption per unit of GDP, indicating that the boost in energy efficiency was faster for these cities after the implementation of a smart city project.

In addition, this study found that smart city projects did not decrease energy consumption in cities located in Eastern China and in cities not belonging to old industrial bases. For policy makers, more importantly, the impacts of smart city projects were slightly better in resource-based cities and in old industrial bases compared to other cities.

In sum, our results suggest that smart city projects are conducive to energy efficiency improvement. Detailed studies are needed to understand how smart city projects affect energy efficiency. More data, such as on other indicators of energy efficiency, are required to confirm the findings of this study. These are the direction for future studies.

Author Contributions: All authors equally contributed to the paper. Z.T., J.K. and R.S. conceptualized the study and carried out initial planning. J.K. retrieved and constructed the dataset. J.K. carried out the statistical analysis, which was refined by R.S. and Z.T. for the final version. J.K. prepared the first draft of the manuscript, which was revised by Z.T. and R.S. All authors reviewed and contributed to the final draft. All authors have read and agreed to the published version of the manuscript.

Funding: We acknowledge funding from the National Social Science Foundation of China (Grant no. 18ZDA051), the National Natural Science Foundation of China (Grant no. 72073049), the National Natural Science Foundation of China (Grant no. 71703052), the National Natural Science Foundation of China (Grant no. 72171100), and the Natural Science Foundation of Hubei Province (Grant no. 2020CFB853). This paper does not reflect an official statement or opinion from the organizations.

Institutional Review Board Statement: Not applicable.

Informed Consent Statement: Not applicable.

Data Availability Statement: The datasets generated during the current study are available from the corresponding author on reasonable request.

Acknowledgments: We thank Botao Liu, Yu Cao, Lang Cheng, Wei Wei, and Dian Jin for their helpful comments on an earlier version of this paper. In addition, Jiayang Kong wants to thank, in particular, the patience, care, and support from Xiaoling Zhu over the years.

Conflicts of Interest: The authors declare no conflict of interest. 


\section{Appendix A}

Descriptive analysis. Panel A of Figure A1 exhibits average yearly energy consumption per unit of GDP in cities participating in a smart city project and cities not participating throughout the entire study period. This figure of these two energy consumption series shows to what extent smart cities affected energy efficiency. Cities that participated in the project had a higher energy consumption level than cities that did not participate at the beginning of study, suggesting that both were affected by distinct developmental trends. The distinction, however, declined slightly over the last six years when more cities participated in smart city project. This implies that smart city projects improved energy efficiency.

A. Smoothing trend in energy consumption per yuan of GDP

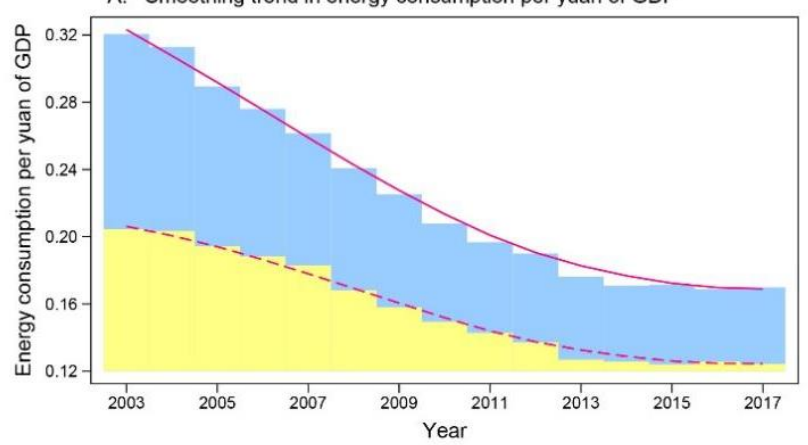

C. Smoothing trend in the share of industrial production in GDP

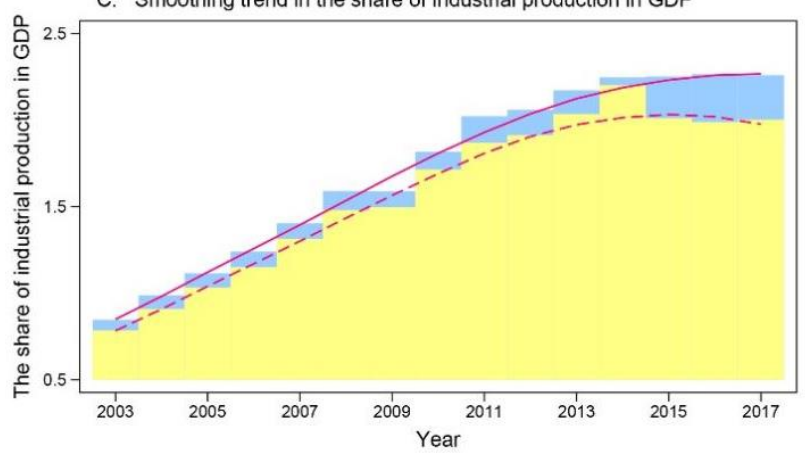

B. Smoothing trend in people density

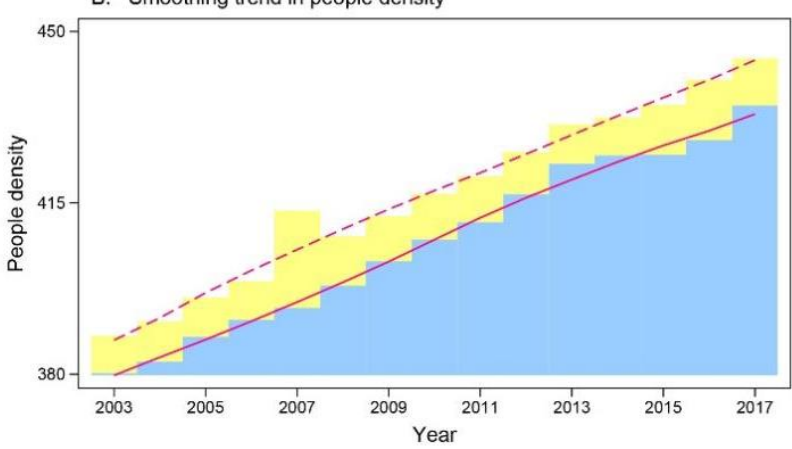

Smoothing trend in the share of industrial sector in GDP

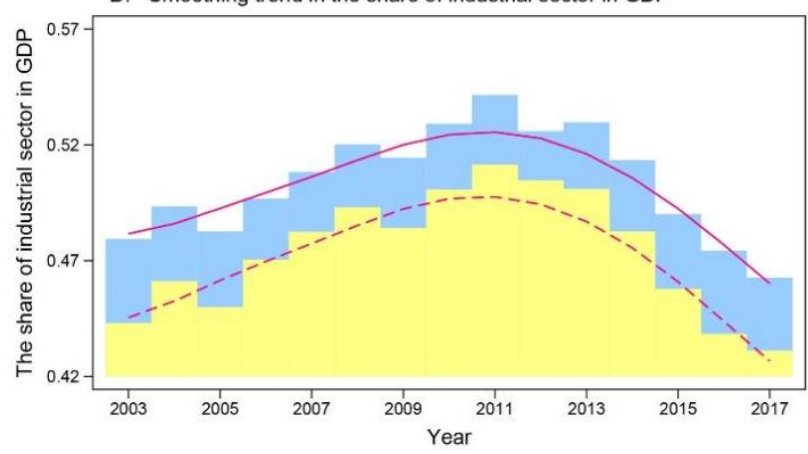

Figure A1. Changes in energy consumption per yuan of GDP, population density, share of industrial production in GDP, and secondary industry as percentage of GDP. The red solid line represents a smoothing trend in the treated cities and the red dash line represents a smoothing trend in the control cities. The blue shadow plots the quantity related to variables in the treated cities and the yellow shadow plots the quantity related to variables in the control cities. (A) Smoothing trend in energy consumption per yuan of GDP. (B) Smoothing trend in people density. (C) Smoothing trend in the share of industrial production in GDP. (D) Smoothing trend in the share of industrial sector in GDP.

Table A1 presents characteristics of the observed cities from 2003 to 2017. The raw data reveal some favorable changes. For example, in the period after the implementation of a smart city project, compared with the period before the project, energy consumption per unit of GDP in the treatment group decreased. This result suggests an improvement in energy efficiency due to the smart city project, which is consistent with the aforementioned observation. 
Table A1. Summary statistics for the main variables used in our analysis.

\begin{tabular}{|c|c|c|c|c|}
\hline & \multicolumn{4}{|c|}{ Treatment Group: Cities Participating } \\
\hline & All the Cities & Before the Project & After the Project & $\begin{array}{l}\text { Control Group: Cities } \\
\text { not Participating }\end{array}$ \\
\hline & (1) & (2) & (3) & (4) \\
\hline \multicolumn{5}{|l|}{$\begin{array}{l}\text { Panel A: Energy efficiency and smart } \\
\text { city projects }\end{array}$} \\
\hline \multirow[t]{2}{*}{$\begin{array}{l}\text { Energy efficiency (tons of standard } \\
\text { coal equivalent } / 10^{4} \text { Yuan) }\end{array}$} & 0.181 & 0.248 & 0.180 & 0.157 \\
\hline & [0.0046] & {$[0.0156]$} & {$[0.0146]$} & {$[0.0034]$} \\
\hline Smart city projects & $\begin{array}{c}0.352 \\
{[0.0074]}\end{array}$ & $\begin{array}{c}0.000 \\
{[0.0000]}\end{array}$ & $\begin{array}{c}1.000 \\
{[0.0000]}\end{array}$ & $\begin{array}{c}0.000 \\
{[0.0000]}\end{array}$ \\
\hline $\begin{array}{c}\text { Panel B. Control variables } \\
\text { People density (persons } / \mathrm{km}^{2} \text { ) }\end{array}$ & $\begin{array}{l}413.429 \\
{[4.8219]}\end{array}$ & $\begin{array}{c}392.064 \\
{[8.180]}\end{array}$ & $\begin{array}{c}436.662 \\
{[12.8381]}\end{array}$ & $\begin{array}{c}416.87 \\
{[6.4112]}\end{array}$ \\
\hline \multirow{2}{*}{$\begin{array}{l}\text { The share of industrial production in } \\
\text { GDP }(\%)\end{array}$} & 1.640 & 1.449 & 2.266 & 1.593 \\
\hline & {$[0.0145]$} & {$[0.0233]$} & {$[0.0414]$} & {$[0.0185]$} \\
\hline \multirow{2}{*}{$\begin{array}{l}\text { The share of the industrial sector in } \\
\text { GDP }(\%)\end{array}$} & 0.485 & 0.507 & 0.4984 & 0.474 \\
\hline & [0.0017] & {$[0.0038]$} & {$[0.0046]$} & {$[0.0021]$} \\
\hline \multicolumn{5}{|l|}{ Panel C. Sample information } \\
\hline Observations & 4215 & 984 & 501 & 2730 \\
\hline Number of cities & 281 & 99 & 99 & 182 \\
\hline
\end{tabular}

\section{References}

1. Urban Development. The World Bank. Available online: https://www.worldbank.org/en/topic/urbandevelopment (accessed on 20 April 2020).

2. Kaza, N. Urban form and transportation energy consumption. Energy Policy 2019, 136, 111049. [CrossRef]

3. Liu, B.; Su, X.; Shi, J.; Hou, R. Does urbanization drive economic growth decoupled from energy consumption in China's logistics? J. Clean. Prod. 2020, 257, 120468. [CrossRef]

4. Ahmad, M.; Rehman, A.; Shah, S.A.A.; Solangi, Y.A.; Chandio, A.A.; Jabeen, G. Stylized heterogeneous dynamic links among healthcare expenditures, land urbanization, and CO2 emissions across economic development levels. Sci. Total Environ. 2020, 753, 142228. [CrossRef] [PubMed]

5. Chen, Z.; Zhou, M. Urbanization and energy intensity: Evidence from the institutional threshold effect. Environ. Sci. Pollut. Res. 2020, 28, 11142-11157. [CrossRef]

6. Lantz, T.L.; Ioppolo, G.; Yigitcanlar, T.; Arbolino, R. Understanding the correlation between energy transition and urbani-zation. Environ. Innov. Soc. Transit. 2021, 40, 73-86. [CrossRef]

7. Liang, W.; Yang, M. Urbanization, economic growth and environmental pollution: Evidence from China. Sustain. Comput. Informatics Syst. 2018, 21, 1-9. [CrossRef]

8. Zheng, W.; Walsh, P.P. Economic growth, urbanization and energy consumption-A provincial level analysis of China. Energy Economics 2019, 80, 153-162. [CrossRef]

9. Cao, Y.; Kong, L.; Zhang, L.; Ouyang, Z. The balance between economic development and ecosystem service value in the process of land urbanization: A case study of China's land urbanization from 2000 to 2015. Land Use Policy 2021, 108, 105536. [CrossRef]

10. Fang, X.; Shi, X.; Gao, W. Measuring urban sustainability from the quality of the built environment and pressure on the natural environment in China: A case study of the Shandong Peninsula region. J. Clean. Prod. 2020, 289, 125145. [CrossRef]

11. Zhao, J.; Xiao, Y.; Sun, S.; Sang, W.; Axmacher, J.C. Does China's increasing coupling of 'urban population' and 'urban area' growth indicators reflect a growing social and economic sustainability. J. Environ. Manag. 2022, 301, 113932. [CrossRef]

12. Chu, Z.; Cheng, M.; Yu, N.N. A smart city is a less polluted city. Technol. Forecast. Soc. Change 2021, 172, 121037. [CrossRef]

13. Lu, C.-W.; Huang, J.-C.; Chen, C.; Shu, M.-H.; Hsu, C.-W.; Bapu, B.T. An energy-efficient smart city for sustainable green tourism industry. Sustain. Energy Technol. Assess. 2021, 47, 101494. [CrossRef]

14. Shamsuzzoha, A.; Nieminen, J.; Piya, S.; Rutledge, K. Smart city for sustainable environment: A comparison of participatory strategies from Helsinki, Singapore and London. Cities 2021, 114, 103194. [CrossRef] 
15. Liu, L.; Zhang, Y. Smart environment design planning for smart city based on deep learning. Sustain. Energy Technol. Assess. 2021, 47, 101425. [CrossRef]

16. Lom, M.; Pribyl, O. Smart city model based on systems theory. Int. J. Inf. Manag. 2021, 56, 102092. [CrossRef]

17. Mora, H.; Mendoza-Tello, J.C.; Varela-Guzmán, E.G.; Szymanski, J. Blockchain technologies to address smart city and society challenges. Comput. Hum. Behav. 2021, 122, 106854. [CrossRef]

18. U.S. and World Population Clock; US Census Bureau. Available online: https:/ / www.census.gov/popclock/ (accessed on 17 June 2020).

19. Global Energy Statistical Yearbook. Available online: https://yearbook.enerdata.net (accessed on 17 March 2020).

20. Zhou, N.; Lu, H.; Khanna, N.; Liu, X.; Fridley, D.; Price, L.; Shen, B.; Feng, W.; Lin, J.; Szum, C.; et al. China Energy Outlook: Understanding China's Energy and Emissions Trends (Ernest Orlando Lawrence Berkeley National Laboratory, 2020). Available online: https:/ / china.lbl.gov/sites/default/files/China\%20Energy\%20Outlook\%202020.pdf (accessed on 2 February 2022).

21. China's Smart Cities Development. The US-China Economic and Security Review Commission. Available online: https: / / www.uscc.gov/research/chinas-smart-cities-development (accessed on 23 January 2021).

22. Yang, J.; Lee, T.-Y.; Zhang, W. Smart Cities in China: A Brief Overview. IT Prof. 2021, 23, 89-94. [CrossRef]

23. Nunes, S.A.S.; Ferreira, F.A.F.; Govindan, K.; Pereira, L.F. “Cities go smart!”: A system dynamics-based approach to smart city conceptualization. J. Clean. Prod. 2021, 313, 127683. [CrossRef]

24. Siokas, G.; Tsakanikas, A.; Siokas, E. Implementing smart city strategies in Greece: Appetite for success. Cities 2020, $108,102938$. [CrossRef]

25. Yu, Y.; Zhang, N. Does smart city policy improve energy efficiency? Evidence from a quasi-natural experiment in China. J. Clean. Prod. 2019, 229, 501-512. [CrossRef]

26. Zhao, M.; Zhou, Y.; Li, X.; Zhou, C.; Cheng, W.; Li, M.; Huang, K. Building a Series of Consistent Night-Time Light Data (1992-2018) in Southeast Asia by Integrating DMSP-OLS and NPP-VIIRS. IEEE Trans. Geosci. Remote Sens. 2019, 58, $1843-1856$. [CrossRef]

27. Gobillon, L.; Magnac, T. Regional Policy Evaluation: Interactive Fixed Effects and Synthetic Controls. Rev. Econ. Stat. 2016, 98, 535-551. [CrossRef]

28. Xu, Y. Generalized Synthetic Control Method: Causal Inference with Interactive Fixed Effects Models. Political Anal. 2017, 25, 57-76. [CrossRef]

29. Athey, S.; Bayati, M.; Doudchenko, N.; Imbens, G.; Khosravi, K. Matrix Completion Methods for Causal Panel Data Models. J. Am. Stat. Assoc. 2021, 116, 1716-1730. [CrossRef]

30. Annavarapu, R.N.; Kathi, S. Cognitive disorders in children associated with urban vehicular emissions. Environ. Pollut. 2016, 208, 74-78. [CrossRef] [PubMed]

31. Dong, H.; Xue, M.; Xiao, Y.; Liu, Y. Do carbon emissions impact the health of residents? Considering China's industrialization and urbanization. Sci. Total Environ. 2021, 758, 143688. [CrossRef] [PubMed] 